\title{
HUBUNGAN ANTARA IKLIM KERJA DENGAN SIKAP KERJA KARYAWAN \\ CV. LAMBIANCE
}

\author{
David Martian Putra ${ }^{1}$ Umbu Tagela $^{2}$ Setyorini $^{3}$ \\ Email: 132015010@student.uksw.edu \\ Fakultas Psikologi, Universitas Kristen Satya Wacana ${ }^{1,2,3}$
}

\begin{abstract}
Abstrak
Jenis penelitian ini adalah penelitian korelasional. Penelitian ini bertujuan untuk mengetahui signifikansi hubungan antara iklim kerja dengan sikap kerja pada keryawan CV. Lambiance. Subjek penelitian yang diambil adalah seluruh karyawan yang berjumlah 68 karyawan. Teknik pengambilan subjek menggunakan total sampling. Alat ukur yang digunakan dalam penelitian ini adalah angket iklim kerjayang diadaptasi berdasarkan teori Benjamin Schneider and C.J. Bartlett dalam Nindya (2012) serta angket sikap kerja yang diadaptasi berdasarkan teori Blum And Naylor dalam Nindya (2012). Teknik analisis data yang digunakan adalah Kendall's tau $b$ dengan bantuan program SPSS for Window Release 20.0. Hasil analisis korelasi menunjukan bahwa antara iklim kerja dengan sikap kerja terdapat hubungan yang positif dan signifikan jadi dapat dikatakan penelitian ini diterima. Hal ini ditunjukkan dengan nilai $r_{x y}=716^{*}$ dan nilai $p=0,00 \leq 0,05$.

Kata Kunci : Iklim Kerja, Sikap Kerja.
\end{abstract}

Abstract

This type of research is correlational research. This study aims to determine the significance of the correation between the working climate with work attitude of on the CV. Lambiance employees. The research subject is taken from all employees, amounting to 68 employees. The subject taking technique uses total sampling. The measuring instrument used in this study is a work climate questionnaire adapted based on the theory of Benjamin Schneider and C.J. Bartlett in Nindya (2012) and work attitude questionnaire adapted based on the theory of Blum And Naylor in Nindya (2012). The data analysis technique used is Kendall's tau b with the help of the SPSS for Window Release 20.0 program. The results of the correlation analysis show that between the work climate and work attitude there is a positive and significant correlation so it can be said that this research is accepted. This is indicated by the value of $\mathrm{rxy}=716^{*}$ and the value of $\mathrm{p}=0.0050 .05$.

Keywords: Work Climate, Work Attitude

PENDAHULUAN

Manusia pada dasarnya selalu berperan aktif dan dominan dalam setiap kegiatan organisasai yang bersifat publik maupun bisnis, karena manusia menjadi perencana, pelaku dan penentu terwujudnya tujuan yang dimiliki oleh perusahaan. Sehingga, sebaik apapun atau secanggih apapun alat yang dimiliki oleh suatu perusahaan, tidak akan memberikan mamfaat yang signifikan kepada perusahaan apabila tidak ada peran aktif dari manusia atau karyawan.

$$
\text { Alfaidah (2007) menjelaskan }
$$

Sumber daya manusia merupakan salah satu sumber daya yang selalu membutuhkan evaluasi, karena merupakan kunci keberhasilan atas suatu perushaaan yaitu melalui pengelolaan sumber daya manusia yang baik. Salah satu tantangan dalam mengelola sumber daya manusia yang berkaitan dengan kebutuhan karyawan adalah bagaimana menciptakan kondisi dan iklim kerja yang dapat memuaskan berbagai kebutuhan karyawan yang berkerja (Handoko, 
2000:2). Iklim kerja merupakan segala sesuatu yang berada di sekitar tenaga kerja yang dapat mempengaruhi dirinya dalam melaksanakan tugas dan pekerjaaan yang dibebankan. Iklim kerja yang nyaman dapat membuat tenaga kerja nyaman dalam bekerja. adapun iklim kerja mempunyai pengaruh langsung terhadap karyawan dalam melaksanakan proses produksi (Sahara,2012). Sehingga, iklim kerja yang nyaman akan membentuk suatu sikap kerja yang baik dan meningkatkan produktivitas karyawan sehingga pekerjaan dapat diselesaikan dengan cepat.

CV L'ambiance di Salatiga yang menjadi obyek penelitian ini, merupakan perusahaan yang bergerak dibidang jasa ekspor mebel. Sebagai suatu perushaan yang di dalamnya terdapat karyawan, perusahaan ini juga tidak terlepas dari masalah iklim kerja dan sikap kerja karyawan. Para karyawan seringkali menghadapi masalah didalam lingkungan kerja, baik dengan rekan sekerja, atasan atau bahkan dengan pekerjaan itu sendiri. Kondisi iklim kerja tersebut dapat disikapi positif atau negatif oleh karyawan yang dapat berpengaruh terhadap kinerja karyawan. Tiap individu memiliki cara sendiri dalam menyikapi masalah yang mereka hadapi, namun perusahaan harus ikut andil dalam menyelesaikan keadaan tersebut agar tercipta suasana dan lingkungan kerja yang kondusif agar dapat disikapi positif oleh karyawan, sehingga karyawan dapat memiliki dan menunjukan sikap kerja yang tinggi di dalam perusahaan.

Berdasarkan gambaran hasil penelitian tersebut, penulis ingin meneliti hubungan iklim kerja dengan sikap kerja karyawan CV. L'ambiance yang bergerak di bidang ekspor mebel.

\section{KAJIAN PUSTAKA}

\section{Sikap Kerja}

J. George, Jones (2012:71) mendefinisikan, "work attitudes are collections of feelings, beliefs, and thoughts about how to behave that people currently hold about their jobs and organizations." Sikap kerja adalah koleksi perasaan, keyakinan, dan pikiran tentang bagaimana berperilaku yang orang saat ini memegang tentang pekerjaan dan organisasi mereka.

$$
\text { James Mocci (2010:54) ''work }
$$
attitudes are the feelings we have toward different aspects of the work environment ${ }^{\text {ee }}$ Sikap kerja adalah perasaan kita kepada aspek yang berbeda dari lingkungan kerja. 
Pangabean (2002:19) "Sikap kerja adalah evaluasi pekerjaan seseorang yang mengekspresikan seseorang perasaan terhadap, keyakinan tentang, dan lampiran pekerjaan seseorang. Sikap kerja merupakan hasil penilaian atau evaluasi terhadap orang-orang, atau kejadian-kejadian ditempat kerja apakah memuaskan, baik, menyenangkan, menguntungkan atau sebaliknya."

Menurut Kreitner dan Kinicki (2008), dijelaskan bahwa "sikap kerja adalah suatu kecenderungan yang dipelajari untuk merespons secara konsisten terhadap sikap yang menyenangkan dan tidak menyenangkan dengan rasa menghargai kepada suatu objek tertentu."

Blum And Naylor dalam Nindya (2012) berpendapat bahwa faktor yang mempengaruhi sikap kerja adalah:

a. Kondisi kerja.

Situasi kerja yang meliputi lingkungan fisik ataupun lingkungan sosial yang menjamin akan mempengaruhi kenyamanan dalam bekerja. Adanya rasa aman dan nyaman akan mempengaruhi semangat dan kualitas karyawan.

b. Pengawasan atasan

Seorang pimpinan melakukan pengawasan terhadap karyawan dengan baik dan penuh perhatian pada umumnya berpengaruh terhadap sikap dan semangat kerja karyawan.

c. Kerja sama dari teman sekerja. teman sekerja yang dapat bekerja sama akan sangat mendukung kualitas dan prestasi dalam menyelesaikan pekerjaan.

d. Keamanan.

Adanya rasa aman yang tercipta serta lingkungan yang terjaga akan menjamin dan menambah ketenangan dalam bekerja.

e. Kesempatan untuk maju. Adanya jaminan masa depan yang lebih baik dalam hal karier baik promosi jabatan dan jaminan hari tua.

f. Fasilitas kerja

Tersedianya fasilitas-fasilitas yang digunakan karyawan dalam pekerjaannya.

g. Gaji

Rasa senang terhadap imbalan yang diberikan perusahaan baik yang berupa gaji pokok, tunjangan dan sebagainya yang akan mempengaruhi sikap karyawan dalam menyelesaikan pekerjaannya.

Berdasar uraian di atas, maka dapat ditarik kesimpulan bahwa faktor-faktor 
yang mempengaruhi sikap kerja karyawan adalah kondisi kerja, pengawasan atasan, kerjasama dari teman sekerja, keamanan, kesempatan untuk maju, fasilitas kerja dan upah /gaji.

\section{Iklim Kerja}

Panudju, (2003: 98) mengemukkan bahwa iklim kerja adalah wilayah kerja yang terbatas pada hubungan antara pekerjaan dengan kondisi tempat pelaksanaan pekerjaan tersebut. iklim kerja dalam pengertian sehari-hari adalah situasi atau keadaan tempat dimana seseorang bekerja.

Nitisemito

(2003:

mengemukakan bahwa iklim kerja adalah segala sesuatu yang ada di sekitar para pegawai dan yang dapat mempengaruhi dirinya dalam menjalankan tugas-tugas yang dibebankan kepadanya.

Toulson dan Smith dalam Nindya (2012) mendefinisikan iklim kerja sebagai suatu yang dapat diukur pada iklim kerja baik secara langsung maupun tidak langsung berpengaruh pada karyawan dan pekerjaannya dimana tempat mereka bekerja dengan asumsi akan berpengaruh pada perilaku karyawan.Liliwery (1999) komunikasi antar pribadi adalah "komunikasi tatap muka antara dua orang atau lebih".
Asri (2006: 73) mengatakan bahwa iklim kerja adalah suatu kondisi dimana di dalamnya para pegawai melaksanakan suatu aktivitas. Kondisi tersebut bisa berupa kondisi material maupun kondisi fisikologis. Dalam hal ini lingkungan kerja adalah berhubungan dengan lingkungan fisik, sehingga manusia dan keterampilan manusia harus mampu memanfaatkan setiap sasaran yang ada secara optimal. Benjamin Schneider and C.J. Bartlett dalam Nindya (2012) mengembangkan 6 dimensi iklim kerja yang terdiri dari :

1. Dukungan

Organisasi

\section{(Organizational Support)}

Hal ini berkaitan dengan keadaan karyawan tentang penghargaan dan pengakuan atas pekerjaan yang baik. Selain itu dukungan perusahaan juga terkait dengan perasaan pegawai bahwa mereka mengetahui apa yang diharapkan dari mereka berkaitan dengan pekerjaan, peranan dan tujuan organisasi.

\section{Kualitas Anggota (Member} Quality)

Berkaitan dengan perasaan karyawan tentang kondisi perusahaan dimana manajemen perusaaan memberikan perhatian kepada pelaksanaan tugas dengan baik, tujuan yang telah ditentukan serta toleransi terhadap kesalahan atau 
hal-hal yang kurang sesuai atau kurang baik.

\section{Keterbukaan (Openness)}

Berkaitan dengan perasaan karyawan mengenai rasa bangga mereka memiliki organisasi dan kesediaan untuk berusaha lebih saat dibutuhkan.

4. Gaya Pengawasan (Supervisory Style)

Hal ini berkaitan dengan perasaan karyawan dengan pengawasan yang dilakukan pada pelaksanaan tugas yang diemban dengan rasa tanggung jawab atas hasil yang dicapai, karena mereka terlibat di dalam proses yang sedang berjalan.

\section{Konflik Anggota (Member}

\section{Conflict)}

Berkaitan dengan hubungan dan interaksi antar anggota di dalam perusahaan serta hubungan antara pimpinan dengan anggota.

\section{Otonomi Anggota (Member} Autonomy)

Otonomi anggota merupakan kondisi organisasi dalam memberikan keleluasan bertindak bagi karyawan serta melakukan penyesuaian diri terhadap tugas-tugas yang diberikan. Hal ini mengacu pada aturan yang ditetapkan organisasi, kebijakan dan prosedur yang ada. Penerimaan terhadap suatu ide-ide yang baru merupakan nilai pendukung di dalam mengembangkan iklim kerja yang kondusif demi tercapainya tujuan organisasi.

\section{Hubungan Antara Iklim Kerja Dengan}

\section{Sikap Kerja}

Aktivitas kerja selalu membutuhkan iklim kerja yang aman dan tentram, olehnya itu setiap organisasi akan menjadikan iklim kerja faktor yang penting dalam mendukung aktivitas organisasi. . Nitisemito (2003: 183) mengemukakan bahwa iklim kerja adalah segala sesuatu yang ada di sekitar para pegawai dan yang dapat mempengaruhi dirinya dalam menjalankan tugas-tugas yang dibebankan kepadanya.

Di dalam iklim kerja perushaan, sikap karyawan bisa dijadikan indikator apakah suatu pekerjaan berjalan lancar atau tidak. Menurut Kreitner dan Kinicki (2008), dijelaskan bahwa sikap kerja adalah suatu kecenderungan yang dipelajari untuk merespons secara konsisten terhadap sikap yang menyenangkan dan tidak menyenangkan dengan rasa menghargai kepada suatu objek tertentu. Jika sikap kerja karyawan baik pekerjaan akan berjalan lancar. Jika tidak berarti akan mengalami kesulitan. Tetapi harus diingat, bukan berarti adanya kesulitan karena karyawan tidak 
memiliki sikap kerja yang baik, melainkan ada masalah lain lagi dalam hubungan antara karyawan yang akibatnya sikap kerjanya diabaikan. Iklim kerja yang terbuka memacu karyawan untuk mengutarakan kepentingan dan ketidakpuasan tanpa adanya rasa takut akan tindakan balasan dan perhatian. Ketidakpuasan seperti itu dapat ditangani dengan cara yang positif dan bijaksana.

Toulson dan Smith dalam Nindya (2012) mendefinisikan iklim kerja sebagai suatu yang dapat diukur pada iklim kerja baik secara langsung maupun tidak langsung berpengaruh pada karyawan dan pekerjaannya dimana tempat mereka bekerja dengan asumsi akan berpengaruh pada perilaku karyawan. Dalam perusahaan sering terjadi kesalahpahaman, adanya kesalahpahaman yang terjadi antara iklim kerja dan sikap karyawan, Memiliki tingkat iklim kerja yang rendah mengakibatkan sikap kerja para karyawan rendah dan sebaliknya.

Dampak dari iklim kerja yang rendah adalah rendahnya sikap karyawan dalam mematuhi tata tertib perusahaan, rendah dalam menentukan target kerja dan rendah dalam memberikan kualitas kerja. Perusahaan yang tidak mampu memberikan iklim kerja yang baik dapat mengakibatkan tidak baik juga sikap kerja yang diberikan oleh karyawan.

Berdasarkan paparan di atas dapat di simpulkan bahwa iklim kerja tinggi maka sikap kerja pun tinggi dan sebaliknya.

\section{METODE PENELITIAN}

Penelitian ini menggunakan jenis penelitian korelasional, dengan jenis penelitian korelasional akan memandu peneliti untuk menyelidiki kemungkinan hubungan iklim kerja dengan sikap kerja karyawan CV. Lambiance. Populasi yang diambil dalam penelitian ini adalah seluruh karyawan CV. Lambiance yang berjumlah 68 karyawan yang terdiri dari 53 karyawan laki-laki dan 15 karyawan perempuan. Teknik pengambilan sampel yang digunakan dalam penelitian ini adalah teknik total sampling yaitu teknik pengambilan sampel dimana jumlah sampel sama dengan populasi yaitu sebanyak 68 karyawan.

Berdasarkan hasil uji validitas item variabel iklim kerja terdapat 18 item (keseluruhan) tergolong valid dengan rentang koefisien korelasi 0,239-0,851. Sedangkan hasil uji validitas item variabel sikap kerja terdapat 21 item (keselurahan) tergolong valid dengan rentang koefisien korelasi 0,215-0,705. Berdasarkan data korelasi tersebut, maka 
item variabel Iklim Kerja dengan Sikap Kerja dinyatakan valid karena koefisien korelasi $\geq 0,20$.

Uji Reabilitas dilihat dari nilai Alpha-Croncbach untuk reabilitas keseluruhan item dalam satu variabel. Pada variabel iklim kerja diperoleh hasil $\alpha=0.884$ dan pada variabel sikap kerja diperoleh hasil $\alpha=0.880$. dilihat dari hasil nilai instrumen tersebut, maka instrumen penelitian ini dapat dikatakan memiliki reabilitas pada kategori bagus karena $\alpha>0.8$.

Teknik analisis data digunakan untuk menjawab rumusan masalah atau menguji hipotesis yang telah dirumuskan. Dalam penelitian ini teknik analisis yang akan digunakan adalah teknik analisis korelasi kendall's tau $b$. Dengan melalui bantuan komputer dengan program SPSS for windows release versi 20 .

\section{HASIL DAN PEMBAHASAN}

Penelitian ini dilakukan di CV. Lambiance, Salatiga, Jawa Tengah. Subjek pada penelitian ini adalah seluruh karyawan CV Lambiance yang berjumlah 68 karyawan.

Data yang diperoleh dalam penelitian ini merupakan hasail analisis dari skala iklim kerja dan sikap kerja. skala ini digunakan untuk mengetahui tingkat iklim kerja dan sikap kerja yang dimiliki oleh karyawan CV Lambiance.

Peneliti mengkategorikan subjek penelitian menjadi 5, yaitu sangat tinggi, tinggi, sedang, rendah, dan sangat rendah.

\section{Analisis Deskriptif Iklim Kerja}

Iklim kerja karyawan diukur dengan menggunakan skala iklim kerja dengan menggunakan empat pilihan jawaban. Skala ini memiliki jumlah pernyataan sebanyak 18 item dengan skor jawaban tertinggi 4 dan skor jawaban terendah 1 .

Berdasarkan hasil data analisis deskriptif iklim kerja di atas diperoleh hasil 10,8 tetapi peneliti membulatkan menjadi 11.

Berdasarkan hasil perhitungan yang telah dilakukan peneliti, didapatkan interval 11 sehingga hasil yang diperoleh sebagai berikut:

Tabel 1. Distribusi Frekuensi Iklim Kerja

\begin{tabular}{|l|c|c|c|}
\hline Kategori & Interval & $\begin{array}{c}\text { Frekue } \\
\text { nsi }\end{array}$ & $\begin{array}{c}\text { Present } \\
\text { ase }(\%)\end{array}$ \\
\hline $\begin{array}{l}\text { Sangat } \\
\text { Tinggi }\end{array}$ & $59-70$ & 19 & 21,1 \\
\hline Tinggi & $47-58$ & 18 & 20 \\
\hline Sedang & $35-46$ & 20 & 22,2 \\
\hline Rendah & $23-34$ & 28 & 31,3 \\
\hline $\begin{array}{l}\text { Sangat } \\
\text { Rendah }\end{array}$ & $11-22$ & 5 & 5,6 \\
\hline Total & 68 & 100 \\
\hline Min & \multicolumn{2}{|c|}{70} \\
\hline Max & & \multicolumn{3}{|l}{} \\
\hline
\end{tabular}


Berdasarkan tabel diatas dapat diketahui bahwa iklim kerja karyawan CV Lambiance sebagian besar berada pada kategori tinggi pada frekuensi 33 karyawan dengan persentase $48,5 \%$.

\section{Analisis Deskriptif Perilaku Bullying}

Sikap Kerja pada karyawan diukur dengan menggunakan skala sikap kerja dengan menggunakan empat pilihan jawaban. Skala ini memiliki jumlah pernyataan sebanyak 21 item dengan skor jawaban tertinggi 4 dan skor jawaban terendah 1 .

Berdasarkan hasil data analisis deskriptif sikap kerja di atas diperoleh hasil 12,6 tetapi peneliti membulatkan menjadi 13.Berdasarkan hasil perhitungan yang telah dilakukan peneliti, didapatkan interval 13 sehingga hasil yang diperoleh sebagai berikut:

Tabel 2. Distribusi Frekuensi Perilaku Bullying

\begin{tabular}{|c|c|c|c|}
\hline $\begin{array}{c}\text { Katego } \\
\text { ri }\end{array}$ & $\begin{array}{c}\text { Interv } \\
\text { al }\end{array}$ & Frekuensi & $\begin{array}{c}\text { Present } \\
\text { ase }(\%)\end{array}$ \\
\hline $\begin{array}{c}\text { Sangat } \\
\text { tinggi }\end{array}$ & $59-72$ & 21 & $31 \%$ \\
\hline Tinggi & $45-58$ & 38 & $55.8 \%$ \\
\hline Sedang & $31-44$ & 9 & $13,2 \%$ \\
\hline Rendah & $27-30$ & 0 & $0 \%$ \\
\hline $\begin{array}{c}\text { Sangat } \\
\text { rendah }\end{array}$ & $13-26$ & 0 & $0 \%$ \\
\hline \multicolumn{2}{|c|}{ Total } & 68 & $100 \%$ \\
\hline \multicolumn{2}{|c|}{ Min } & 13 \\
\hline
\end{tabular}

\section{\begin{tabular}{|c|c|}
\hline Max & 72 \\
\hline
\end{tabular}}

Berdasarkan tabel 4,3 Distribusi

Frekuensi dapat diketahui bahwa sikap kerja karyawan CV Lambiance sebagian besar berada pada kategori tinggi pada frekuensi 38 karyawan dengan persentase $55,8 \%$.

Dilihat berdasarkan deskripsi data tabel kategorisasi tingkat iklim kerja dan sikap kerja, tingkat iklim kerja sangat rendah sebesar $0 \%$, tingkat rendah sebesar 8,8\%, pada kategori sedang terdapat $35,4 \%$, pada kategori tinggi terdapat $48.5 \%$, dan pada kategori sangat tinggi terdapat 7,3\%. Dari paparan di atas menunjukkan bahwa secara sebagian besar tingkat iklim kerja tergolong dalam kategori tinggi. Hal ini menunjukkan bahwa karyawan CV. Lambiance sebagian besar memiliki iklim kerja yang tinggi.

Variabel selanjutnya yaitu sikap kerja, menunjukkan hasil tingkat sikap kerja pada kategori sangat rendah sebesar $0 \%$, kategori rendah sebesar $0 \%$, pada kategori sedang terdapat $13,2 \%$, pada kategori tinggi terdapat 55,8\%, dan pada kategori sangat tinggi terdapat $31 \%$. Dari paparan diatas dapat disimpulkan bahwa sebagian besar karyawan CV. Lambiance memiliki tingkat sikap kerja dengan kategori tinggi. 
Berdasarkan uji hipotesis yang telah dilakukan, menunjukkan hasil bahwa terdapat hubungan positif dan signifikan antara iklim kerja dengan sikap kerja. Diketahui koefisien korelasi antara iklim kerja dengan sikap kerja sebesar 716 dengan demikian hipotesis alternatif diterima dan berbunyi terdapat hubungan yang signifikan antara iklim kerja degnan sikap kerja CV. Lambiance Salatiga.

\section{PENUTUP}

Berdasarkan hasil penelitian ini maka penelitian ini mendukung Toulson dan Smith dalam Nindya (2012) menyatakan iklim kerja sebagai suatu yang dapat diukur pada lingkungan kerja baik secara langsung maupun tidak langsung berpengaruh pada karyawan dan pekerjaannya dimana tempat mereka bekerja dengan asumsi akan berpengaruh pada motivasi dan perilaku karyawan." Karena seseorang dalam suatu organisasi atau perusahaan harus memiliki iklim kerja yang dapat membuat karyawan mampu bekerja dengan baik serta memiliki lingkungan yang baik guna mendukung karyawan dalam berkerja. Dalam iklim kerja yang tinggi dapat mengurangi resiko terjadi kesalahpahaman, adanya kesalahpahaman yang terjadi antara karyawan dengan atasan atau karyawan dengan karyawan yang lainy. Iklim kerja yang nyaman dapat membuat tenaga kerja nyaman dalam bekerja. Sahara (2012) berpendapat adapun iklim kerja mempunyai pengaruh langsung terhadap karyawan dalam melaksanakan proses produksi. Hal ini merupakan salah satu indikasi pentingnya menciptakan iklim kerja yang tinggi dalam suatu perusahaan. Memiliki iklim kerja yang tinggi menghasilkan sikap kerja yang tinggi.

Besarnya koefisien korelasi di atas dapat diartikan bahwa variabel X skornya tinggi dan variabel $\mathrm{Y}$ skornya tinggi. Berdasarkan hasil tersebut, bisa diartikan semakin tinggi iklim kerja maka semakin tinggi sikap kerja yang terjadi. Demikian pula sebaliknya semakin rendah iklim kerja maka semakin rendah sikap kerja yang terjadi. Karena ketika iklim kerja tinggi karyawan dapat melakukan pekerjaanya dengan baik, hal ini menyebabkan karyawan memiliki sikap kerja yang baik terhadap perusahaan. Namun bila perusahaan memiliki iklim kerja yang rendah atau tidak kondusif, maka hal ini berpengaruh pada sikap kerja yang rendah juga terhadap perusahaan.

Hasil penelitian diatas mendukung penelitian yang dilakukan oleh: Nindya Laksana (2012) dengan penelitiannya 
yang berjudul hubungan iklim organisasi terhadap motivasi dan sikap kerja karyawan CV. Fajar Kurnia menunjukkan nilai koefisien korelasi sebesar 0,767 untuk motivasi kerja dengan sikap dan 0,704 untuk korelasi antara iklim kerja motivasi kerja. Nilai probabilitas kedua korelasi adalah 0,000 dengan $\alpha=0,05$, sehingga nilai $\mathrm{p}<0,05$.

Berdasarkan kesimpulan di atas, maka peneliti mengajukan beberapa saran sebagai tindak lanjut dari penelitian ini sebagai berikut. Perusahaan mampu memberikan layanan agar dapat menumbuhkan iklim kerja dan sikap kerja yang baik di dalam perusahaan. Perusahaan perlu melakukan kegiatan yang dapat meningkatkan iklim kerja yang dapat meningkatkan sikap kerja karyawan. Perushaan diharapkan membuat suatu layanan yang sesuai dengan karakteristik serta permasalahan karyawan khususnya mengenai iklim kerja maupun sikap kerja.

Berdasarkan hasil temuan dalam penelitian ini, penulis menyarankan agar karyawan lebih dapat meningkatkan dan menjaga iklim kerja dan menunjukan sikap kerja yang baik dengan bekerja dengan baik dan sesuai karget untuk dapat membawa iklim kerja yang baik dan sikap kerja yang tinggi pula.
Berdasakan hasil temuan dalam pujm nenelitian ini, penulis menyarankan agar peneliti selanjutnya dapat meneliti mengenai hubungan iklim kerja dengan sikap kerja karena penulis memiliki asumsi bahwa suatu perusahaan yang memiliki iklim kerja yang tinggi dapat meningkatkan sikap kerja atau dapat meneliti dengan variabel lain terhadap iklim kerja atau yang lainya .

\section{DAFTAR PUSTAKA}

A. Judge Timothy. Job Attitudes. by Annual Reviews, 2012.

Alfaidah, F, 2007. Pengaruh Kepuasan Kerja Karyawan Terhadap Produktifitas Kerja Pada Karyawan Koperasi Argo Niaga Jabung Malang. Fakultas Ekonomi Universitas Islam Negeri Malang

Aniek, 2008. Sikap Kerja Perawat https://klinis.wordpress.com/2008 /01/02/ sikap- kerja-perawat/. Diakses Pada Tanggal 12 Maret 2019.

Asri, Marwan, 2006. Pengelolaan Pegawai. Yogyakarta : BPFEUGM.

Azwar, Saifudin .2015. Metode Penelitian. Yogyakarta: Pustaka Belajar. . 2015. Reliabilitas dan Validitas. Yogyakarta: Pustaka Belajar.

George J., G. Jones. Understanding and Magahing Organizational Behavior. New York: Pearson Education, Inc., 2012. 
George and Jones. (2005). Understanding and Managing Organizatiional Behaviour. 4th Edition. Prentice Hall.

Gerorge, Mallery. 1995. SPSS/PC, Step by step : A Simple Guide and Reference. Balmont: Wadsworth Publishing Company.

Gibson, James L., Jhon M. Ivancenvinch, James H. Donely, JR. Organization : Structur, Processes, Behavior, Dallas : Business Publications, Inc, 1973.

Handoko, T. Hani, 2000. Managemen Sumber Daya Manusia. Edisi 2. Cetakan Ksebelas. BPFE, Yogyakarta.

Kreitner and Kinicki. (2008). Organization Behaviour 8th Edition. McGraw Hill International.

Laksana, Nindya, 2012. Hubungan Iklim Organisasi Terhadap Motivasi Dan Sikap Kerja Karyawan Cv. Fajar Kurnia. Fakultas Keguruan dan Ilmu Pendidikan Universitas Satyawacana.

Luthans Fred. Organizational Behavior, 11th Ed. Singapore: McGrawHill/Irwin, 2005.

Mocci James. The Proncipil Of Management. New York: By Free Press, 2010.

Narbuko Cholid dan Abu Achmadi. 2009. Metodologi Penelitian. Jakarta : PT Bumi Aksara.

Nitisemito. A, 2003. Manajemen Personalia. Yogyakarta : BPFEUGM.

Pangabean, Mutiara Sibarani. 2002. Manajemen Sumber Daya
Manusia, Ghalia Indonesia, Bogor Selatan.

Panudju. Agung, 2003. Budaya Organisasi. Jakarta : Rajawali Press.

Robbins, Stephen P, 2002 Perilaku Organisasi: Konsep, Kontroversi, Aplikasi.(Alih bahasa: Dr. Hadyana Pujaatmaka). Jakarta: Prenhallind

Sahara, Y, 2012. Pengaruh Lingkungan Kerja Terhadap Produktifitas Kerja Karyawan (Kasus: Karyawan Bagian Produksi PT. Asia Forestama Raya Pekan Baru)

Sofyan Yamin dan Heri Kurniawan, 2009. SPSS COMPLETE Teknik Analisis Statistik Terlengkap dengan Softwere SPS. Jakarta, SALEMBA INFOTEK

Sugiyono. 2006. Metode Penelitian Kuantitatif, Kualitatif dan R \& D. Bandung: Alfabeta 2011. Metode Penelitian Administrasi. Bandung: Alfabeta.

2012. Statistika untuk Penelitian. Bandung: Alfabeta.

Theedens. R, 2009. Manajemen Sumber Daya Manusia Berbasis Proses. Jakarta : Grasindo.

Wirawan, 2009. Evaluasi Kinerja Sumber Daya Manusia. Jakarta : Salemba Empat.

WISNA, W, S. Pengaruh Lingkungan Kerja Dan Perilaku Kerja Terhadap Kinerja Pegawai Pada Kantor Sekretariat Daerah Kabupaten Konawe Utara. Jurnal Manajemen dan Ekonomi. Vol.2 No.2 Maret 2018. ISSN No. 2597 4173 